\title{
Assessing Knowledge Conveyed in Gesture: Do Teachers Have the Upper Hand?
}

\author{
Martha Wagner Alibali \\ Carnegie Mellon University
}

\author{
Lucia M. Flevares and Susan Goldin-Meadow \\ University of Chicago
}

\begin{abstract}
Children's gestures can reveal important information about their problem-solving strategies. This study investigated whether the information children express only in gesture is accessible to adults not trained in gesture coding. Twenty teachers and 20 undergraduates viewed videotaped vignettes of 12 children explaining their solutions to equations. Six children expressed the same strategy in speech and gesture, and 6 expressed different strategies. After each vignette, adults described the child's reasoning. For children who expressed different strategies in speech and gesture, both teachers and undergraduates frequently described strategies that children had not expressed in speech. These additional strategies could often be traced to the children's gestures. Sensitivity to gesture was comparable for teachers and undergraduates. Thus, even without training, adults glean information, not only from children's words but also from their hands.
\end{abstract}

How does a skilled teacher identify when a child experiences a "teachable moment" and decide what type of instruction to offer that child? For instruction to be beneficial, it must be timed appropriately vis-à-vis the child's developing knowledge. Further, to be maximally effective, the type of instruction must mesh appropriately with the knowledge the child brings to the learning situation (Kuhn, 1972; Turiel, 1969). However, despite the importance of the match between the child and the learning environment (Hunt, 1961), little is known about the sources of information that teachers use, both to gauge when a particular child is ready to learn and to decide what type of instructional input to offer that child.

The notion of readiness to learn is present in many theories of developmental change. For example, in the Piagetian view, the "teachable moment" is one characterized by disequilibrium, or instability of knowledge. During periods of disequilibrium, children are hypothesized to be especially receptive to input from the environment that helps them

Martha Wagner Alibali, Department of Psychology, Carnegie Mellon University; Lucia M. Flevares and Susan Goldin-Meadow, Department of Psychology, University of Chicago. Lucia $\mathbf{M}$. Flevares is now at the Department of Educational Psychology, University of Illinois at Urbana-Champaign.

This research was supported by Grant R01 HD 18617 from the National Institute of Child Health and Human Development and by a grant from the Spencer Foundation. We thank Cynthia Lubin for assistance in transcribing and coding the videotape data and Lisa Haverty, Spencer Kelly, and William Meadow for their thoughtful comments on the article itself. Portions of this research were presented at the 1995 Meeting of the Society for Research in Child Development, Indianapolis, Indiana.

Correspondence concerning this article should be addressed to Martha Wagner Alibali, Department of Psychology, Carnegie Mellon University, Pittsburgh, Pennsylvania 15213. Electronic mail may be sent via Internet to alibali+@andrew.cmu.edu. resolve inconsistencies in their knowledge structures and propels them toward a more stable state (Piaget, 1964/1967, 1975/1985). Although the Piagetian account does not emphasize the social origins of new knowledge, many studies have shown that the social environment can play a role in the process of equilibration (e.g., Perret-Clermont \& Brossard, 1985). A teacher who recognizes that a child is in a state of disequilibrium could offer appropriate input to the child and thus facilitate the child's advance to a more stable and more correct knowledge state.

More recent approaches to the study of development attempt to characterize children's changing knowledge structures in precise, operational terms. Early efforts in this vein described children's knowledge in terms of functional structures that children use in solving problems (Strauss, 1972). Later work within the information-processing tradition has focused on the nature of the strategies that children use to solve conceptual problems (e.g., Siegler \& Jenkins, 1989; Siegler \& Shrager, 1984). Strikingly, across a variety of theoretical approaches, one consistent finding has been that periods of conceptual transition are characterized by variability (see Goldin-Meadow \& Alibali, 1995, for discussion). Thus, readiness to learn has been associated with variability in the functional structures that children use to arrive at solutions (Strauss \& Rimalt, 1974), variability across problems in verbally reported strategies (Siegler, 1995 ), and variability within a single problem in the strategies expressed in speech and in the accompanying gestures (Church \& Goldin-Meadow, 1986; Perry, Church, \& Goldin-Meadow, 1988). For example, several studies have shown that children who frequently produce mismatches between gesture and speech in their problem explanations, expressing one strategy in one modality and a second strategy in the other modality, are more likely to benefit from instruction about the problems than children who seldom 
produce mismatches (Church \& Goldin-Meadow, 1986; Perry et al., 1988).

The particular type of variability that is manifested in gesture-speech mismatches is of interest, not only because it indicates variability within a single response but also because it suggests that the two strategies may have unequal representational status. Karmiloff-Smith (1992) has argued that behavior can be influenced by different levels of knowledge, including both explicit knowledge, which can be expressed in speech, and implicit knowledge, which is embedded in problem-solving procedures. Spontaneous gestures appear to be one modality through which implicit knowledge can be communicated (Alibali, Garber, \& Goldin-Meadow, 1993; Goldin-Meadow \& Alibali, 1994). Indeed, recent work indicates that developing knowledge is often expressed in gesture before it is expressed in speech (Alibali \& Goldin-Meadow, 1993; Church, 1987). Under this view, spontaneous gestures that mismatch speech reflect knowledge that is implicitly held and that is likely to be made more explicit, or "redescribed," over development (Karmiloff-Smith, 1992). Thus, gestures that mismatch speech are a particularly noteworthy type of variability in a child's behavior because they provide - at least for experimenters-a window onto precisely those aspects of the child's knowledge that are ready to undergo redescription.

However, it remains an open question as to whether teachers, parents, and others who work with children are sensitive to the messages conveyed in gesture. It is possible that untrained observers would be unable to detect such subtle behavioral variability. If so, the insights gesture offers about a child's openness to instruction and about the aspects of the child's knowledge that are ripe for change would be inaccessible to common experience.

Even though children's gestures can reveal important information about their knowledge, few studies have investigated whether untrained observers can actually grasp the content of a child's gestures. Instead, most research on sensitivity to gesture has focused on the observer's ability to decode the emotional cues and attitudes conveyed in gestures (see Feyereisen \& de Lannoy, 1991, for a review). For example, the Profile of Nonverbal Sensitivity Test, developed and used extensively by Rosenthal and colleagues (Rosenthal, Hall, DiMatteo, Rogers, \& Archer, 1979), measures sensitivity to nonverbal expressions of emotion in a variety of channels, including the hands.

One published study has examined whether adults are sensitive to the content of children's gestures (GoldinMeadow, Wein, \& Chang, 1992). This study provided evidence that adults can decode the information that children express uniquely in gesture on Piagetian conservation tasks. However, although the results of this study are suggestive, there are several reasons why they are not definitive, particularly in the context of teachers and others who work with children in classroom settings. First, the task that was the focus of the study, Piagetian conservation, is not a task that is part of a typical school curriculum. Second, the stimuli used in the study were vignettes of children in an experimental setting rather than in a typical classroom setting. Third, it remains unclear whether the adults' responses were actually based on the children's gestures or whether they were based on the adults' own general knowledge of conservation.

The present study was designed to examine whether teachers and other adults can grasp the content of children's gestures and use that information in assessing their knowledge. Our primary goal was to examine adults' sensitivity to the gestures that children produced when explaining a task that is traditionally a central part of the elementary school curriculum-mathematical equations-in a situation that occurs routinely in the classroom-working at the blackboard. This study is the first to explore adult sensitivity to the substantive, task-related information that children convey in the gestures they spontaneously produce in a typical academic environment.

A second goal of the present study was to examine whether teachers are more sensitive than other adults to the information that children convey in gesture. One might expect that, given their experience evaluating children's knowledge, teachers would be especially sensitive to the information that children express in gestures. Although the sample studied by Goldin-Meadow et al. (1992) included some teachers, there were too few to reliably test for differences between teachers and other adults. In this study, we therefore tested a sufficient number of adults ( 20 teachers and 20 adults who were not teachers) to examine group differences in adults' sensitivity to children's gestures.

A third goal of the present study was to address an important methodological weakness of the previous research. Goldin-Meadow et al. (1992) argued that adults were able to decode the content of the gestures children produce on Piagetian conservation tasks. However, they could not rule out the possibility that the adults' assessments were based on their own general knowledge of conservation rather than on the specific information conveyed in the children's gestures. The present study was designed to allow us to distinguish between these two possibilities with respect to the math task.

In summary, in this study, we investigate whether adults are sensitive to the mismatch between gesture and speech in children's explanations of an academic task, and we examine whether adults can interpret the specific information that children express in their gestures. We also investigate whether teachers are more likely than nonteachers to be sensitive to information conveyed in children's gestures. In general, we note that spontaneous gesture is likely to be a natural, evolved form of human communication (cf. Donald, 1991). This study explores whether this modality is sufficiently accessible to the untrained observer (teacher or nonteacher) that it can fulfill its potential as an important component of educational practice.

\section{Method}

\section{Participants}

Twenty undergraduate students (11 women, 9 men) and 20 current or former teachers ( 12 women, 8 men) participated. The teachers had an average of 6 years of teaching experience (range 6 
months to 15 years). Eleven of the teachers taught at the elementary level, and 9 at the secondary level. None of the participants had any training in coding gesture.

\section{Procedure}

Participants were tested individually. Each was told that the purpose of the study was to examine adults' assessments of children's knowledge about mathematical equations and that the study involved viewing videotaped vignettes of children explaining their solutions to mathematics problems. Before viewing the vignettes, each adult was shown examples of the types of problems the children would be explaining in the vignettes: $4+5+8=\ldots+$ 8 and $3+6+5=3+$

The stimulus tape (described below) contained vignettes of 13 children. The first vignette served as a practice trial and was used to ensure that the participants understood the task. Participants' responses to this vignette are not included in the analyses reported below. The remaining 12 vignettes served as the stimuli for the study. Each vignette was shown twice to ensure that the tape could be heard and seen clearly. Before each vignette, the experimenter placed a sheet of paper that displayed the math problem used in that vignette on a small easel on the table. After each vignette, the experimenter asked the participant to assess the child's reasoning about the problem. The math problem remained on the easel for the participants to refer to during their response if they desired. The adults' responses were videotaped. Adults were asked to assess children's knowledge verbally rather than simply to rate children's readiness to learn, because pilot research showed that adults' ratings were not associated with children's readiness to learn, as reflected in gesture and speech (see also Goldin-Meadow et al., 1992).

\section{Stimulus Tape}

The stimuli for the study were videotaped vignettes of 12 different fourth-grade children ( 6 boys and 6 girls), each explaining his or her solution to a single math problem. The vignettes were culled from the data described by Alibali and GoldinMeadow (1993). In each vignette, the problem and the child's solution appeared on the blackboard in front of the child. Because we were interested in appraisals of children who had not yet mastered the task and who would therefore need instruction in the task, the vignettes were chosen to include only those children who gave incorrect solutions to each of the math problems.

The speech and gestures of the children in the vignettes had been coded by using systems established in previous work (Alibali \& Goldin-Meadow, 1993; Perry et al., 1988). The vignettes were selected so that, in speech, all of the children described strategies leading to incorrect solutions. Six of the children said that they added all of the numbers in the problem, which we have termed the add-all strategy (e.g., on the problem $5+6+7=\ldots+7$, one child said, "I added 5 plus 6 is 11,11 plus 7 is 18 , and then I added 18 plus 7 equals 25 "). The remaining six children said that they added the numbers up to the equal sign, which we have termed the add-to-equal-sign strategy (e.g., on the same problem, one child said, "I added 5 plus 6 is 11, plus 7 equals 18"). In all the vignettes, the children's incorrect solutions were consistent with the strategies they expressed in speech.

The vignettes were chosen so that six children produced gestures that conveyed the same strategy as they expressed in their speech (matching stimuli), and six children produced gestures that conveyed a different strategy than they expressed in their speech (mismatching stimuli; see Table 1). The six matching stimuli portrayed three children who produced an add-all strategy and three who produced an add-to-equal-sign strategy in both speech and gesture. The six mismatching stimuli were similarly divided

Table 1

Sample Vignettes of Each Type From the Stimulus Tape

\begin{tabular}{|c|c|c|}
\hline Type of vignette and problem & Child's speech & Child's gesture \\
\hline $\begin{array}{l}\text { Match } \\
\quad(\text { add-all/add-all) } \\
3+4+5=3+\end{array}$ & $\begin{array}{l}\text { " } 3 \text { plus } 4 \text { is } 7 \text {, plus } 5 \text { is } \\
12 \text {, plus } 3 \text { equals } 15 " \\
\text { (add-all). }\end{array}$ & $\begin{array}{l}\text { Right hand point to left } 3,4,5 \text {, } \\
\text { right } 3 \text {, solution, retract (add- } \\
\text { all). }\end{array}$ \\
\hline $\begin{array}{l}\text { Match } \\
\text { (add-to-equal-sign/add-to- } \\
\text { equal-sign) } \\
\begin{array}{l}4+5+8=\ldots+8 \\
\text { Mismatch }\end{array}\end{array}$ & $\begin{array}{l}\text { " } 4 \text { plus } 5 \text { is } 9,9 \text { plus } 8 \\
\text { is } 17 " \text { (add-to-equal- } \\
\text { sign). }\end{array}$ & $\begin{array}{l}\text { Left hand point to } 4,5 \text {, left } 8 \text {, } \\
\text { solution, retract (add-to-equal- } \\
\text { sign). }\end{array}$ \\
\hline $\begin{array}{l}\text { (add-all/add-to-equal-sign) } \\
6+3+4=-4\end{array}$ & $\begin{array}{l}\text { " } 6 \text { plus } 3 \text { is } 9 \text {, plus } 4 \text {, } \\
13 \text {, plus } 4,17 " \text { (add- } \\
\text { all). }\end{array}$ & $\begin{array}{l}\text { Right hand point to } 6,3 \\
\text { retract (add-to-equal- }\end{array}$ \\
\hline $\begin{array}{l}\text { Mismatch } \\
\qquad \begin{array}{l}\text { (add-all/equalize) } \\
5+6+7=\ldots+7\end{array}\end{array}$ & $\begin{array}{l}\text { "I added } 5 \text { plus } 6 \text { is } 11 \text {, } \\
11 \text { plus } 7 \text { equals } 18 ; \\
\text { then I added } 18 \text { plus } \\
7 \text { equals } 25 " \text { (add-all). }\end{array}$ & $\begin{array}{l}\text { Right hand point to } 5,6 \text {, left } 7 \text {, } \\
\text { retract. Right hand point to } \\
\text { solution, right } 7 \text {, solution, } \\
\text { retract (equalize). }\end{array}$ \\
\hline $\begin{array}{l}\text { Mismatch } \\
\text { (add-to-equal-sign/add-all) } \\
7+6+4=7+\end{array}$ & $\begin{array}{l}\text { "7 plus } 6 \text { equals } 13,13 \\
\text { plus } 4 \text { equals } 17 " \\
\text { (add-to-equal-sign). }\end{array}$ & $\begin{array}{l}\text { Left hand point to left } 7 \text {, first } \\
\text { plus, } 6 \text {, second plus, } 4 \text {, right } 7 \text {, } \\
\text { solution, retract (add-all). }\end{array}$ \\
\hline $\begin{array}{l}\text { Mismatch } \\
\text { (add-to-equal-sign/grouping) } \\
4+3+9=-+9\end{array}$ & $\begin{array}{l}\text { "I added } 4 \text { plus } 3 \text { is } 7, \\
\text { plus } 9 \text { more is } 16 " \\
\text { (add-to-equal-sign). }\end{array}$ & $\begin{array}{l}\text { Right hand point to } 4,3 \text {, retract. } \\
\text { Right hand point toward } \\
\text { solution, retract (grouping). }\end{array}$ \\
\hline
\end{tabular}


on the basis of speech: Three portrayed children who produced an add-all strategy in speech, and three portrayed children who produced an add-to-equal-sign strategy in speech. In the mismatching vignettes, among the children who produced an add-all strategy in speech, one child produced an add-to-equal-sign strategy in gesture (by pointing to the addends on the left side of the equation), and two children produced an equalize strategy in gesture. The equalize strategy focuses on making both sides of the problem equal (e.g., by indicating the two distinct sides of the equation in two separate gestures). Among the children who produced an add-to-equal-sign strategy in speech, one child produced an add-all strategy in gesture (by pointing to all the addends on both sides of the equation), and two children produced a grouping strategy in gesture. The grouping strategy focuses on grouping the addends that would yield the correct solution (e.g., by pointing to the two addends that could be summed to arrive at the correct solution). Examples of each type of vignette are presented in Table 1.

Note that the strategies expressed in the children's spoken explanations were incorrect in each of the 12 vignettes. The only consistent difference between the matching and mismatching stimuli was whether gesture conveyed the same strategy as the speech (matching stimuli) or a different strategy (mismatching stimuli). Thus, if adults responded differently to the two types of stimuli, this difference must reflect an ability to detect information conveyed solely in gesture.

For the undergraduates, four versions of the stimulus tape were created, each with the vignettes in a different order. There were no differences in the pattern of results across the four versions; therefore, we have collapsed across orders in the results presented below. All 20 teachers viewed the vignettes in the same order.

\section{Coding and Analysis}

We coded the speech and gestures that the adults produced in describing each child's reasoning, using a system based on that used to code children's explanations on the math task (Perry et al., 1988). Adults' spoken responses were coded independently of gesture (using only the audio portion of the tape), and their gestured responses were coded independently of speech (using only the video portion of the tape).

Our coding focused on the adults' descriptions of the content of the children's knowledge, specifically, the strategies that children used to solve the problems. Adults' spoken responses were coded for statements about strategies the children understood or used and statements about strategies the children did not understand or use. Each child on the tape used either the add-all strategy or the add-to-equal-sign strategy to solve the problem and expressed one of these two strategies in his or her spoken explanation. In assessing the children's knowledge, adults often attributed to a child either the add-all strategy (e.g., "He added all the numbers up, including the one on the right side of the equation, to fill in the blank") or the add-to-equal-sign strategy (e.g., "She just added the digits on the left side of the equation"). At times, the adults also commented that a child did not understand a particular strategy, such as the equalize strategy (e.g., "He doesn't differentiate between things on either side of the equation; he doesn't realize that he has to balance them out") or the grouping strategy (e.g., "I think she can add the numbers, but I think she's missing the grouping"). Some of the adults' responses also contained information about the children's personalities or prior school experience; these comments were noted but not included in the analysis.

Adults' gestured responses were also coded in terms of the strategies that they conveyed. The most common strategies adults expressed in gesture were the add-all strategy (e.g., a long sweep- ing gesture under the entire problem or a string of points to each of the addends in the problem), the add-to-equal-sign strategy (e.g., a sweeping gesture under the left side of the problem or a string of points to each of the addends on the left side of the problem), the equalize strategy (e.g., a tensed hand held over the left side of the problem and then over the right side of the problem), and the grouping strategy (e.g., a V-shaped, two-finger point to the two addends that could be grouped to provide the correct answer).

For some vignettes, participants gestured in neutral space (the space in front of their bodies) and not to the problem on the easel. Some of these gestures did not convey strategies but had only a regulatory or discourse function (i.e., "beat" gestures; see McNeill, 1992); these gestures were noted but not included in the analysis. Other gestures in neutral space did convey strategies, including the add-all strategy (e.g., a long sweeping gesture from left to right across all of neutral space, representing summing all the addends), the add-to-equal-sign strategy (e.g., a short sweeping gesture across left neutral space, ending with an abrupt downward motion, representing adding and then stopping at the equal sign), or the equalize strategy (e.g., both hands cupped in neutral space, with alternating up and down movements, representing balancing the two sides of the equation). To develop the coding categories for strategic gestures in neutral space, we asked a pilot sample of adults to assess the children's reasoning without having the math problems available to gesture toward. For each strategy, we then identified the types of gestures that most frequently accompanied the verbal expression of that strategy. The coding categories developed in this pilot work were used to code the gesture in the present study independently of the accompanying speech.

In analyzing the data, we evaluated the adults' spoken and gestured responses in relation to the strategies that children expressed in their speech. Thus, each of the adults' responses was coded as a repetition of the strategy that the child expressed in the speech, an addition to the strategy that the child expressed in the speech, or both.

Repetitions of the strategy in the child's speech. A repetition was coded when the adult expressed the same strategy (in speech, gesture, or both) that the child had expressed in speech. For example, when describing a girl who expressed the add-all strategy in speech, one adult said "She's seeing all the plus signs, and she's automatically thinking that you add all the numbers together with the plus signs," while making a sweeping gesture under the entire problem.

Adults sometimes produced repetitions in gesture and not in speech. For example, when describing a girl who expressed the add-all strategy in speech, one adult did not express any strategy in speech (saying, "The student was confused with the meaning of the equation") but repeated the child's add-all strategy in his own gesture (by making a sweeping gesture under all of the addends in the problem).

Additions to the child's speech. An addition was coded when the adult expressed a strategy (in speech, gesture, or both) that the child in the vignette had not expressed in speech (although the child might have expressed the strategy in gesture). In almost all spoken additions, the adults stated that a child had not used or not understood a strategy that the child had not expressed in speech. For example, when describing a child who expressed the add-all strategy in speech, one adult noted that the child did not understand the equalize strategy: "He doesn't understand the equal sign-that the two sides have to-that what's on the left and what's on the right have to be equal." At first glance, it may seem strange that adults frequently commented on the absence of particular strategies in children's reasoning, particularly given that their task was 
to assess the children's reasoning about the problems. However, from an instructional standpoint, it seems likely that, if asked to teach a particular child, adults might focus their initial assessments, and therefore their instruction, on just those strategies that they believe the child does not understand.

In a very small number of responses (fewer than $1 \%$ ), the adult stated that a child had used or understood a strategy that the child had not expressed in speech. For example, when describing a child who expressed the add-all strategy in speech for the problem $6+$ $3+4=\ldots+4$, one adult attributed the add-to-equal-sign strategy to the child in her own speech, saying "I didn't hear him add that 4 (indicates right 4). I think he just ignored that." These responses were also coded as additions. It is important to note that, except for these very few responses, all of the adults' spoken additions made correct inferences about the reasoning that the children expressed in speech. For example, in describing a child who expressed the add-all strategy in speech, if one assumes that children's speech is an accurate index of what they understand, it is in fact correct to assert that the child does not understand the equalize strategy or the grouping strategy.

Many adults produced both repetitions and additions in the same response. For example, when describing a boy who expressed an add-all strategy in speech, one adult said "He added all of the numbers together to get the answer here. He still isn't thinking along the lines that this (indicates left side of problem) equals this (indicates right side)." In this response, the adult provided a repetition of the child's add-all strategy in his own speech and provided an addition, the equalize strategy, in both speech and gesture. As another example, when describing a girl who expressed an add-to-equal-sign strategy in speech for the problem $7+6+4=7+\ldots$, one adult said "She added just the first three (sweeping gesture under left side) and ignored the second part of the equation, the $7+$ (sweeping gesture under entire problem)." In this response, the adult expressed the repetition (the add-to-equalsign strategy) in speech and in the first part of her gestured response, and expressed the addition (the add-all strategy) in the second part of her gestured response, that is, in the sweeping gesture under the entire problem.

None of the 480 responses produced by the adults was entirely nonstrategic. In 9 responses, the adults did not describe a strategy in their speech. However, in each of these responses, the adult conveyed a strategy in the accompanying gesture. Responses of this type were infrequent and occurred following both matching stimuli ( $n=6)$ and mismatching stimuli $(n=3)$. In 40 responses, the adults produced gestured responses that did not convey strategies (i.e., that consisted only of beat gestures). However, in each of these responses, the adult conveyed a strategy in the accompanying speech. Responses of this type were equally frequent following matching stimuli $(n=21)$ and mismatching stimuli $(n=19)$.

\section{Reliability}

Reliability was assessed by having a second observer indepen. dently code a randomly selected subset of three gestured responses and three verbal responses for each of the adult participants (25\% of the complete data set). The second coder was blind to the strategy expressed in the child's speech in each vignette. Interrater agreement was $94 \%(n=121)$ for coding spoken strategies, $86 \%$ $(n=114)$ for identifying responses that conveyed strategies in gesture, and $80 \%(n=98)$ for coding the particular strategies in those gestured responses.

\section{Results}

The results are organized around three issues. We first examine whether adults were sensitive to the relationship between gesture and speech in the children's explanations. We then consider similarities and differences in the teachers' and undergraduates' responses. Finally, we examine whether the adults were sensitive to the specific content of the gestures that the children produced and whether the adults' responses were derived from the adults' own knowledge about equations or from the children's gestures.

\section{Do Adults Go Beyond Speech in Assessing Children's Knowledge?}

Adults were highly accurate at detecting the strategies children expressed in speech. Both teachers and undergraduates accurately repeated or paraphrased children's spoken strategies for virtually all of the vignettes, both matching and mismatching. Only one adult response in the entire sample did not include a repetition of the child's strategy in at least one modality.

To examine whether the adults went beyond children's speech in assessing their knowledge, we analyzed the data using 2 (subject group: teachers vs. undergraduates) $\times 2$ (stimulus type: matching vs. mismatching) analysis of variance, with stimulus type as a repeated measure. Figure 1

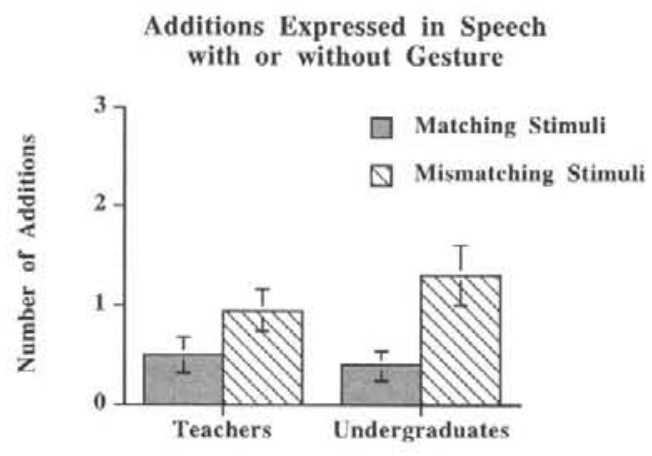

Additions Expressed Uniquely in Gesture

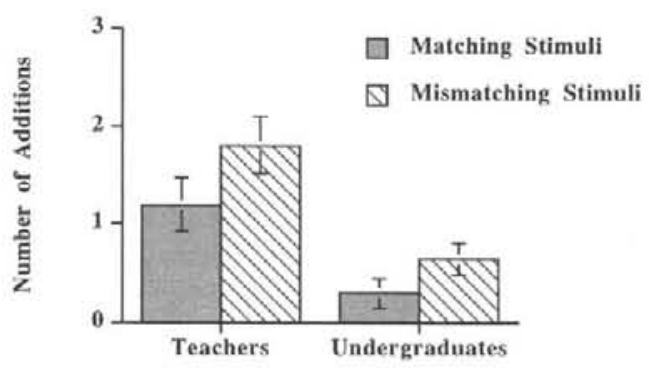

Figure 1. Number of responses in which teachers and undergraduates expressed additions in speech (either with or without accompanying gesture, top panel) or uniquely in gesture (bottom panel). The error bars represent standard errors. 
presents the data separately for additions expressed by the adults in speech (either speech alone or speech and gesture together; top panel) and additions expressed by the adults uniquely in gesture (bottom panel). On each measure, both teachers and undergraduates produced more additions in response to stimuli in which gesture and speech mismatched than in response to stimuli in which gesture and speech matched; $F(1,38)=33.38, p<.001$, for additions expressed in speech, $F(1,38)=7.24, p<.02$, for additions expressed uniquely in gesture. Thus, both teachers and undergraduates appear to notice the gestures children produce in a typical classroom setting.

Note that whenever an addition is expressed uniquely in gesture, by definition, it does not convey the same strategy as the accompanying speech and is therefore itself a gesture-speech mismatch. Thus, the adults produced more mismatches of their own when describing children who produced mismatches than when describing children who produced matches (see also Goldin-Meadow et al., 1992).

\section{Do Teachers and Undergraduates Differ in Their Sensitivity to Gesture?}

Contrary to expectation, teachers appeared to be no more sensitive to children's gestures than undergraduates who were not teachers. Group differences in sensitivity to the relationship between gesture and speech would have been reflected in a significant interaction between subject group and stimulus type. The test of this interaction was marginally significant in the opposite direction for the additions expressed in speech measure, $F(1,38)=3.71, p<.07$, and was not significant for the additions expressed uniquely in gesture measure, $F(1,38)=0.50, p>.45$.

However, before accepting the absence of significant interaction effects as evidence for the absence of group differences in sensitivity, it is important to consider whether these tests had adequate power to detect such an effect. Each test is based on four means, each of which represents 20 observations. With $\alpha=.05$, each test of the interaction has power of .88 to detect an effect of size $f=.50$ (Cohen, 1988). It therefore appears that the study did have adequate power to detect an interaction effect (albeit one of large size). It should be noted that the test of the interaction uses the smaller within-subjects error term rather than the larger between-subjects error term (which is used to test the effect of subject group); thus, an effect of size $f=.50$ would be relatively small in real terms. Thus, the absence of significant interactions can sensibly, but cautiously, be interpreted as the absence of group differences in sensitivity to the relationship between gesture and speech.

To further assess the relationship between teaching experience and sensitivity to information conveyed in gesture, we examined whether length or type of teaching experience influenced teachers' responses to the two types of stimuli. Teachers were divided into two experience categories on the basis of a median split (less than 5 years vs. 5 years or more). As expected, teachers in both experience groups expressed more additions in response to mismatching than matching stimuli, $F(1,18)=11.50, p<.005$; however, there was no interaction between experience group and stimulus type, $F(1,18)=0.24, p>.50$. A comparison of elementary and secondary school teachers also revealed no interaction between grade level taught and stimulus type, $F(1,18)=0.22, p>.50$.

Thus, length or type of experience with children in the classroom did not predict how sensitive adult participants were to the children's mismatching gestures. Instead, teachers with few years of experience and teachers with many years of experience differentiated between the matching and mismatching stimuli to an equal extent, as did elementary and secondary school teachers. Indeed, undergraduates and teachers at all experience levels appeared to be similar in their sensitivity to gesture-speech mismatches.

\section{Do Adults' Additions Reflect the Knowledge That the Children Expressed in Gesture?}

We next consider the source and the content of the adults' additions. We suggest that the children's gestures may have cued the adults' additions. If this is the case, the strategies that the adults express in their additions should be able to be traced back to the strategies the children expressed in gesture. We found that 49 of the 94 additions the adults produced in response to mismatching explanations (52\%) were "traceable" to the children's gestures. For example, a child in one of the vignettes produced an add-all strategy in speech and an equalize strategy in gesture. One adult described this child as follows: "He doesn't understand the equal sign-that the two sides have to-that what's on the left and what's on the right have to be equal." In his speech, this adult described the very strategy that the child had expressed uniquely in gesture (equalize). Note that in this example of a traceable addition, the adult denies that the child understands a strategy that the child had actually produced in gesture; 18 of the 49 traceable additions were of this type. In fact, in only 1 traceable addition did the adult explicitly attribute to the child knowledge of the strategy that the child had produced in gesture.

The most common type of traceable addition (30 of 49) occurred when the adult reproduced the child's gestured strategy in his or her own gestures without commenting on it at all in speech. For example, in describing a child who produced an add-to-equal-sign strategy in speech and a grouping strategy in gesture on the problem $4+3+9=$ +9 , one adult described the child's spoken add-to-equalsign strategy in his own speech (by saying, "She added up all the numbers on the left side and said that it was equal to this blank, again forgetting about the additional sum on the right") and reiterated the grouping strategy that the child had produced in gesture in his own gestures (by pointing at the 4 and the 3 , the two numbers that can be added to obtain the correct answer). In cases of this sort, the adults neither denied nor attributed the child's gestured strategy to the child but rather seconded it in an implicit fashion through their own gestures. We consider at the end of this section whether these seconded gestures were merely unthinking 
copies of the children's gestures or considered (albeit implicit) renditions of those gestures.

As noted above, just over half $(52 \%)$ of the adults' additions to mismatching stimuli could be traced to the children's gestured strategies. In the remaining additions, the new strategy that the adult expressed differed from the child's gestured strategy and thus could not have been drawn directly from the child's gestures. For example, in describing a child who produced an add-all strategy in speech and an equalize strategy in gesture, one adult mentioned the grouping strategy, saying, "He summed them to the space he needed, instead of realizing that since the $4 \mathrm{~s}$ are the same, he just needed to add the 6 and the 3." Because this grouping strategy could not be directly traced to the child's gestures, the adult presumably drew on her own general knowledge about math problems of this type in generating the addition.

Given that some of the adult additions must have been drawn from general knowledge, it is possible that even the additions that appeared on the surface to be traceable to the children's gestures could also have been based on the adults' own general knowledge. To evaluate this possibility, we paired each child who produced a gesture-speech mismatch on the stimulus tape with a child who produced the same strategy in speech but in a gesture-speech match. For example, Child 3 and Child 4 on the stimulus tape each produced an add-to-equal-sign strategy in speech; however, Child 3 produced a grouping strategy in gesture (a mismatching stimulus), whereas Child 4 produced an add-toequal-sign strategy in gesture (a matching stimulus). These two children were paired for our analysis. For each pair, we then determined how often the adults' responses to the child with the matching gestures contained the strategy conveyed in the paired child's mismatching gestures. Thus, for the pair in the example above, we determined how often the adult participants mentioned a grouping strategy when describing each of these two children. In this way, adults' responses to the matching stimuli in each pair provided an estimate of the "base rate" for mentioning particular strategies when those strategies were not prompted or cued by the child's gestures.

Across the six pairs, adults were significantly more likely to express a given strategy when describing a child who actually expressed that strategy in gesture than when describing the paired child who did not express that strategy; 1.23 versus 0.28 responses, $F(1,38)=25.64, p<.001$. In fact, of the 27 adults (16 teachers and 11 undergraduates) who produced additions that could be traced back to a child's gestures, 23 produced more additions traceable to gesture for mismatching stimuli than comparable additions for the control matching stimuli. Two adults produced an equal number of additions for both types of stimuli, and only 2 adults showed the nonpredicted pattern $(p<.001$, Binomial Test). Thus, the adults did indeed appear to be generating many of their additions on the basis of the gestures the children produced, rather than on the basis of their own general knowledge of equations.

Finally, it is possible that the adults whose additions were based on the children's gestures did not actually decode the information conveyed in those gestures but simply imitated the gestures without processing them. However, a subset of the adults' responses provides evidence against this hypothesis. In 19 of the adults' 49 additions that were based on the children's gestures, the information conveyed in the child's gestures was translated into speech. That is, the additions were expressed either in speech alone or in gesture and speech together. In these responses, the adults were clearly not mimicking the form of the children's gestures but instead had decoded the content and incorporated it into their verbal assessment of the child.

Although many of the adults' additions traceable to gesture were translated into speech, there remained a substantial subset ( 30 of 49 , or $61 \%$ ) that were expressed uniquely in gesture. For example, in describing a girl who expressed the add-to-equal-sign strategy in speech and the add-all strategy in gesture, one adult repeated the child's add-toequal-sign strategy in his own speech (by saying, "She just added the first three [addends] and ignored the second part of the equation") but conveyed the child's gestured add-all strategy in his own gesture (by making a long sweeping gesture from left to right under all of the addends in the problem on the easel). It is possible that responses of this type were in fact simple copies of the gestures the children produced in the vignettes. Alternatively, the adults could have expressed the same content that the children expressed in their gestures but in a different form. To evaluate whether the adults' gestured additions were simple copies of the children's gestures, we compared the adults' gestured additions that were traceable to the children's gestures with the actual gestures that the children in those vignettes had produced.

We compared each traceable gestured addition produced by an adult with the corresponding child's gesture along six dimensions: (a) the placement of the gesture (toward the problem or in neutral space), (b) the hand used to produce the gesture (right, left, or both), (c) the handshape used (point, palm, etc.), (d) the type of motion used (sweep, point, etc.), (e) the direction of motion (right to left, both directions, etc.), and (f) the order in which the components of the equation were indicated. For each response, we determined the number of dimensions that the adult altered when reproducing the child's gestures.

In only one response was the adult's gesture identical to the child's on all six dimensions. Moreover, in this response, the adult appeared to be deliberately imitating the child's mismatch; the adult said, "She went ..." and then reproduced the child's speech and gesture exactly. Thus, when an adult intended to mimic a child's gesture, the adult could achieve a perfect imitation. In each of the remaining 29 traceable gestured responses, the adults altered between one and six dimensions $(M=3.2)$ when expressing the child's gestured strategy. Thus, on average, the adults' gestured responses differed from the children's in more than three ways. This lack of overlap between the child and adult renditions of the same strategy is particularly impressive given that the adult rendition had to contain enough of the same information as the child's to be considered traceable in the first place. 
Thus, the adults did not simply mimic the children's gestures. Instead, even when they expressed in their own gestures the same strategy that the child had expressed in gesture, they tended to produce that gesture differently. For example, consider one adult's description of a child who produced an equalize strategy in gesture by moving his left hand under the left side of the equation and then moving his right hand under the right side of the equation. The adult also expressed the equalize strategy in gesture but in a different way: She held her right hand in a tensed spreadfinger handshape over the left side of the equation displayed on the easel and then over the right side of the equation. Both child and adult conveyed the equalize strategy by gesturing toward the problem; however, the adult and child differed in the hand they used to gesture (the child used both hands, whereas the adult used her right hand), the type of motion (the child used a sweeping motion, whereas the adult used no motion), and so forth.

In summary, both teachers and undergraduates frequently produced additions that could be traced to the gestures of the children in the vignettes. More than a third of these traceable additions were expressed in speech by the adults; the remainder were expressed in gesture. However, even when adults expressed their additions in gesture, these gestures were not exact copies of the gestures that the children had produced. Thus, the adults not only noticed the information that the children expressed in gesture but they also processed that information-as shown by the fact that they redescribed it either across modalities (from gesture to speech) or within a modality (from one type of gesture to another).

\section{Discussion}

We have found that both undergraduates and teachers are sensitive to the information that children express in gesture and not in speech. Moreover, the adults demonstrated this sensitivity when assessing the knowledge of children participating in a typical academic task, in a typical classroom setting. Children's gestures thus appear to be a source of information that educators can use (and presumably do use) in making assessments of children's knowledge in the classroom. This research represents the first step toward investigating how teachers' instructional efforts are influenced by knowledge children express implicitly rather than explicitly.

Note, however, that in terms of generalizing our results to classroom interactions, the presentation of gesture in our study was not completely naturalistic because the gestures had been preselected, and they were each presented twice on videotape. In this regard, it is important to point out that a recent study of adults viewing children's "live" explanations of conservation problems suggests that adults are able to detect and interpret the information children express in gesture even when viewing unedited, spontaneous interactions (Goldin-Meadow \& Sandhofer, 1997).

When assessing the knowledge of children who produced gesture-speech mismatches, the adults in our study frequently mentioned strategies that the children had not ex- pressed in speech. Thus, the adults appeared to recognize, at some level, that children who produce gesture-speech mismatches have more than one strategy in their individual repertoires. Moreover, many of the additions that the adults produced could actually be traced to the gestures produced by the children, suggesting that the adults were often sensitive to the specific strategies that the children expressed in gesture. Thus, the adults were responsive, at a general level, to the variability that children displayed across modalities and, at a more specific level, to the particular strategies that children expressed in their gestures. In these ways, children's gestures provide information, not only to scientists and observers trained in coding gesture but also to adults who have had no experience coding gesture and who have not even been instructed to pay attention to gesture.

In this study, teachers' and undergraduates' assessments of the children's knowledge were similar in several respects. Both groups of participants were highly accurate at repeating the strategies that children expressed in speech. Both groups also detected and responded to mismatches between gesture and speech in the stimulus vignettes. Both undergraduates and teachers attributed to children strategies that they had not expressed in speech more often when describing children who produced gesture-speech mismatches than when describing children who produced gesture-speech matches. Furthermore, for both groups, those strategies could often be traced to the children's gestures. Thus, by interpreting children's gestures in relation to their speech, both groups of adults not only noticed that the two groups of children differed in terms of their knowledge about the problems but they also gained specific knowledge about the particular strategies that children expressed in gesture.

Interestingly, the teachers were no more effective than the undergraduates at detecting children's gesture-speech mismatches. At first glance, this finding seems surprising given that teachers have both more experience with children and more knowledge about learning processes than undergraduates. However, from another perspective, the lack of difference between the groups suggests that integrating knowledge from both modalities is, in fact, a basic feature of the human communication system. We turn next to this issue.

\section{Integrating Information From Both Gesture and Speech}

Our results provide experimental support for McNeill's (1992) theoretical claims about the relationship between gesture and speech. McNeill has argued that gesture and speech together form a single, unified system and that within this system, gestures and speech are coexpressive. Both modalities contribute to convey a speaker's intended meaning, and the overall meaning is a synthesis of the information presented in the codified, linear, segmented speech mode and the information presented in the idiosyncratic, holistic, relational gestural mode. McNeill and colleagues (McNeill, 1992; McNeill, Cassell, \& McCullough, 1994) have further argued that listeners carry out this same synthesis. That is, in the process of speech comprehension, 
listeners synthesize the information presented in speech and in gesture to form a single, unified representation.

Under this view, the ability to combine information presented in the verbal and gestural modalities is an integral and natural part of the process of communication, and thus requires no particular cultural or professionalizing experiences to cultivate it (cf. Geary, 1995). As a result, it is not all that surprising that teachers of varied experience levels, as well as undergraduates with no formal teaching experience, are able to carry out this integration. Our results indicate that both teachers and undergraduates were readily able to glean information from children's gestures. Other recent work indicates that even children are responsive to other children's gestures (Kelly \& Church, in press) as well as teachers' gestures (Berch, Singleton, \& Perry, 1995; Fernandez, Flevares, Goldin-Meadow, \& Kurtzberg, 1996).

Indeed, many of the adults who participated in this study actually remarked on the children's gestures in their assessments of the children's knowledge. Fourteen of the 40 adults explicitly mentioned the children's gestures in at least 1 of the 12 assessments, and a total of $5 \%$ of all responses included some explicit mention of the children's gestures. Moreover, in several cases, the adults mentioned the same aspects of the gestures that trained gesture coders used in assessing children's gestured strategies. For example, in describing a boy who expressed the add-all strategy in speech and the equalize strategy in gesture, one undergraduate said, "He seemed to notice that there was an equal sign because he used both arms." In describing a girl who expressed the add-to-equal-sign strategy in speech and the add-all strategy in gesture in explaining her solution to the problem $7+6+4=7+\ldots$, the same undergraduate said, "Her finger sort of scanned over the [right] 7 , and she ignored it. So I think that she notices that there are two $7 \mathrm{~s}$, but instead of canceling it out on both sides, she only canceled it out on the right side." Although examples such as these were not frequent, they suggest that at least some of the adults were aware of the fact that the children produced gestures, and that these gestures conveyed substantive information about their understanding of the problems.

Although many of the adults noticed the children's gestures, many others seemed not to be aware of the fact that they were detecting and interpreting the children's gestures. Indeed, when they were debriefed, many adults claimed that they had not noticed that the children gestured or that they had not been paying attention to the children's gestures. Even though adults differed in their explicit awareness of gesture, we found that adults who mentioned the children's gestures $(n=14)$ were not more sensitive to children's gesture-speech mismatches than adults who did not mention the children's gestures $(n=26)$. Both groups produced comparable numbers of additions overall, $F(1,38)=0.63$, $p>.40$, and differentiated equally well between matching and mismatching stimuli, $F(1,38)=0.001, p>.90$. Thus, being explicitly aware of gesture does not appear to be a prerequisite for decoding gesture. However, further empirical work on this issue is needed.

\section{The Role of Gesture in the Learning Environment}

Children's gestures are particularly revealing when they convey information that is not expressed in speech, as in the present study, or when the accompanying speech is inarticulate or vague. This is often the case when children are working out a new idea (Crowder \& Newman, 1993) or discovering a new strategy (Siegler \& Jenkins, 1989) and are ready to benefit from instruction (Alibali \& Perrott, 1996; Graham \& Perry, 1993). In previous work, we have argued that a child's gestures provide an observable index of the aspects of the child's knowledge that are ripe for development-specifically, those strategies that the child may be able to apply, given assistance from an adult or a more capable peer (Goldin-Meadow, Alibali, \& Church, 1993). In this sense, children's gestures provide an observable index of the contents of what Vygotsky (1978) has termed the child's zone of proximal development. The present study demonstrates that adults can detect the cues to a child's zone of proximal development that are provided by the child's gestures.

We further suggest that the assessments adults form on the basis of the child's gestures and speech may influence how they go about instructing that child. The adults in our study often described strategies that they believed the children in the vignettes did not understand. It seems quite likely that, if asked to instruct a particular child, adults might focus their instruction on the specific strategies they believe the child not to understand. If a child's gestures prompt an adult to think about a particular strategy, that strategy may be at the top of the adult's agenda when he or she decides how to instruct that child.

For example, consider how one of the teachers described the reasoning of a boy who solved the problem $5+6+7=$ +7 and who expressed the add-to-equal-sign strategy in speech and the grouping strategy in gesture. The teacher explained that the child did not understand the grouping strategy: "What I'm picking up now is [the child's] inability to realize that these (indicates 5 and 6) are meant to represent the same number... there isn't a connection being made by the fact that the 7 on this side of the equal sign (indicates left side) is supposed to also be the same as this 7 on this side of the equal sign (indicates right side), which would, you know, once you made that connection it should be fairly clear that the 5 and 6 belong in the box." Note that, at some level, the teacher was incorrect-the child did indeed have an understanding, however implicit, of the grouping strategy (an understanding that the child expressed uniquely in gesture). However, the fact that the teacher did not explicitly recognize the child's grasp of this strategy might not matter if, in instructing the child, the teacher was to highlight the grouping strategy - that is, if the teacher was to point out that, because there are equivalent addends on the two sides of the equation, those addends can be canceled and the other addends can be grouped. Instruction about the grouping strategy might be especially effective for this particular child because it would help him to transform or "redescribe" his emerging knowledge about grouping 
into a problem-solving procedure that he can apply and articulate in speech (see Karmiloff-Smith, 1992).

Furthermore, from an instructional point of view, it may not matter whether a teacher denies that a child understands a strategy that the child did produce in gesture or seconds that strategy by reproducing it in his or her own gestures. Either way, the strategy is active in the teacher's thoughts and thus may influence the teacher's choice of material to be taught or stressed. This, however, is an empirical question, one that would be well worth investigating. Do teachers, in fact, make different instructional choices after having implicitly acknowledged that a strategy is part of the child's repertoire (by reproducing the child's gestured strategy in their own gestures) than they do after having explicitly denied (in their speech) that the child has any knowledge of the strategy? In this regard, it should be noted that, when asked to instruct a child on this math task, teachers sometimes convey information in their own gestures that differs from the information they convey in speech (Fernandez et al., 1996). Preliminary evidence suggests that these teacher mismatches have an impact on the child, evoking different reactions than do matches or statements that contain speech and no gesture.

In summary, the gestures that a child produces may provide teachers with information about the specific type of instruction that the child would find beneficial. Moreover, even if a teacher does not pick up on the specific strategies that a child expresses in gesture, the teacher may be aware, at a more global level, that the child's gesture does not match the speech it accompanies (see also Perry, Woolley, \& Ifcher, 1995). The mismatch between gesture and speech in a child's explanations may offer the teacher valuable information about the stability of that child's knowledge; specifically, variability across modalities may serve as a signal to teachers (as it does to experimenters) that a particular child is in an unstable knowledge state and is ready to profit from instruction. Given this signal, the teacher may then alter his or her instruction to the child, although the instruction would not, in this case, be specifically tailored to the child's emerging knowledge.

We have shown that, when assessing a child's knowledge about an academic task, adults make use of the information children convey in their gestures as well as their speech. Through their gestures, children provide their teachers with important clues about their developing knowledge and, as a result, about the timing and type of instruction that might be most beneficial. Children's gestures thus offer a readily available source of information that teachers can use, both to identify when children are ready to learn, and to decide how to make the most of the "teachable moment".

\section{References}

Alibali, M. W., Garber, P., \& Goldin-Meadow, S. (1993, March). Implicit knowledge displayed in gesture sets the agenda for learning. Paper presented at the biennial meeting of the Society for Research in Child Development, New Orleans, LA.

Alibali, M. W., \& Goldin-Meadow, S. (1993). Transitions in learn- ing: What the hands reveal about a child's state of mind. Cognitive Psychology, 25, 468-523.

Alibali, M. W., \& Perrott, M. A. (1996, June). The structure of children's verbal explanations reveals the stability of their knowledge. Paper presented at the annual symposium of the Jean Piaget Society, Philadelphia, PA.

Berch, D., Singleton, J. L., \& Perry, M. (1995, March). Many hands make learning math easy. Paper presented at the biennial meeting of the Society for Research in Child Development, Indianapolis, IN.

Church, R. B. (1987). Gesture-speech mismatch and transitional knowledge. Unpublished doctoral dissertation, University of Chicago.

Church, R. B., \& Goldin-Meadow, S. (1986). The mismatch between gesture and speech as an index of transitional knowledge. Cognition, 23, 43-71.

Cohen, J. (1988). Statistical power analysis for the behavioral sciences. Hillsdale, NJ: Erlbaum.

Crowder, E. M., \& Newman, D. (1993). Telling what they know: The role of gesture and language in children's science explanations. Pragmatics and Cognition, 1, 341-376.

Donald, M. (1991). Origins of the modern mind: Three stages in the evolution of culture and cognition. Cambridge, MA: Harvard University Press.

Fernandez, E., Flevares, L. M., Goldin-Meadow, S., \& Kurtzberg, T. (1996, April). The role of the hand in teacher-student interaction. Paper presented at the annual meeting of the American Educational Research Association, New York.

Feyereisen, P., \& de Lannoy, J.-D. (1991). Gestures and speech: Psychological investigations. New York: Cambridge University Press.

Geary, D. C. (1995). Reflections of evolution and culture in children's cognition: Implications for mathematical development and instruction. American Psychologist, 50, 24-37.

Goldin-Meadow, S., \& Alibali, M. W. (1994). Do you have to be right to redescribe? [Review of the book Beyond modularity.] Behavioral and Brain Sciences, 17, 718-719.

Goldin-Meadow, S., \& Alibali, M. W. (1995). Mechanisms of transition: Learning with a helping hand. In D. Medin (Ed.), The psychology of learning and motivation (Vol. 33, pp. 115-157). New York: Academic Press.

Goldin-Meadow, S., Alibali, M. W., \& Church, R. B. (1993). Transitions in concept acquisition: Using the hand to read the mind. Psychological Review, 100, 279-297.

Goldin-Meadow, S., \& Sandhofer, C. M. (1997). The role of gesture in communicating a child's thoughts to an onlooker. Manuscript submitted for publication.

Goldin-Meadow, S., Wein, D., \& Chang, C. (1992). Assessing knowledge through gesture: Using children's hands to read their minds. Cognition and Instruction, 9, 201-219.

Graham, T. A., \& Perry, M. (1993). Indexing the state of transitional knowledge. Developmental Psychology, 29, 779-788.

Hunt, J. M. (1961). Intelligence and experience. New York: Ronald Press.

Karmiloff-Smith, A. (1992). Beyond modularity: A developmental perspective on cognitive science. Cambridge, MA: MIT Press.

Kelly, S. D., \& Church, R. B. (in press). Can children detect conceptual information conveyed through other children's nonverbal behaviors? Cognition and Instruction.

Kuhn, D. (1972). Mechanisms of change in the development of cognitive structures. Child Development, 43, 833-844.

McNeill, D. (1992). Hand and mind. Chicago: University of Chicago Press.

McNeill, D., Cassel1, J., \& McCullough, K.-E. (1994). Communi- 
cative effects of speech-mismatched gestures. Research on Language and Social Interaction, 27, 223-237.

Perret-Clermont, A.-N., \& Brossard, A. (1985). On the interdigitation of social and cognitive processes. In R. A. Hinde, A.-N. Perret-Clermont, \& J. Stevenson-Hinde (Eds.), Social relationships and cognitive development (pp. 309-327). Oxford, England: Clarendon Press.

Perry, M., Church, R. B., \& Goldin-Meadow, S. (1988). Transitional knowledge in the acquisition of concepts. Cognitive Development, 3, 359-400.

Perry, M., Woolley, J., \& Ifcher, J. (1995). Adults' abilities to detect children's readiness to learn. International Journal of Behavioral Development, 18, 365-381.

Piaget, J. (1967). Six psychological studies (A. Tenzer, Trans., \& D. Elkind, Ed.). New York: Random House. (Original work published in 1964).

Piaget, J. (1985). The equilibration of cognitive structures (T. Brown \& K. J. Thampy, Trans.). Chicago: University of Chicago Press. (Original work published in 1975).

Rosenthal, R., Hall, J. A., DiMatteo, M. R., Rogers, P. L., \& Archer, D. (1979). Sensitivity to nonverbal communication: The PONS test. Baltimore: Johns Hopkins University Press.

Siegler, R. S. (1995). How does change occur? A microgenetic study of number conservation. Cognitive Psychology, 28, 225-273.
Siegler, R. S., \& Jenkins, E. (1989). How children discover new strategies. Hillsdale, NJ: Erlbaum.

Siegler, R. S., \& Shrager, J. (1984). Strategy choices in addition and subtraction: How do children know what to do? In C. Sophian (Ed.), Origins of cognitive skills (pp. 229-293). Hillsdale, NJ: Erlbaum.

Strauss, S. (1972). Inducing cognitive development and learning: A review of short-term training experiments: 1 . The organismicdevelopmental approach. Cognition, 1, 329-357.

Strauss, S., \& Rimalt, I. (1974). Effects of organizational disequilibrium training on structural elaboration. Developmental Psychology, 10, 526-533.

Turiel, E. (1969). Developmental processes in the child's moral thinking. In P. Mussen, J. Langer, \& M. Covington (Eds.), Trends and issues in developmental psychology (pp. 92-133). New York: Holt, Rinehart \& Winston.

Vygotsky, L. S. (1978). Mind in society. Cambridge, MA: Harvard University Press.

Received February 1, 1996

Revision received May 24, 1996

Accepted June 21, 1996 